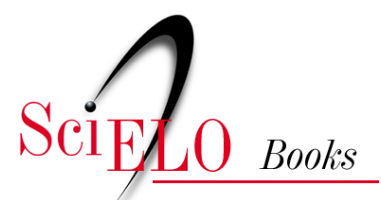

\title{
23. Varíola: uma Doença Extinta
}

\author{
Joffre Marcondes de Rezende
}

\section{SciELO Books / SciELO Livros / SciELO Libros}

REZENDE, J. M. Varíola: uma Doença Extinta. In: À sombra do plátano: crônicas de história da medicina [online]. São Paulo: Editora Unifesp, 2009, pp. 227-230. História da Medicina series, vol. 2. ISBN 978-85-61673-63-5. https://doi.org/10.7476/9788561673635.0024.

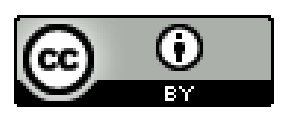

All the contents of this work, except where otherwise noted, is licensed under a Creative Commons Attribution 4.0 International license.

Todo o conteúdo deste trabalho, exceto quando houver ressalva, é publicado sob a licença Creative Commons Atribição 4.0.

Todo el contenido de esta obra, excepto donde se indique lo contrario, está bajo licencia de la licencia Creative Commons Reconocimento 4.0. 


\title{
Variola: uma Doença Extinta
}

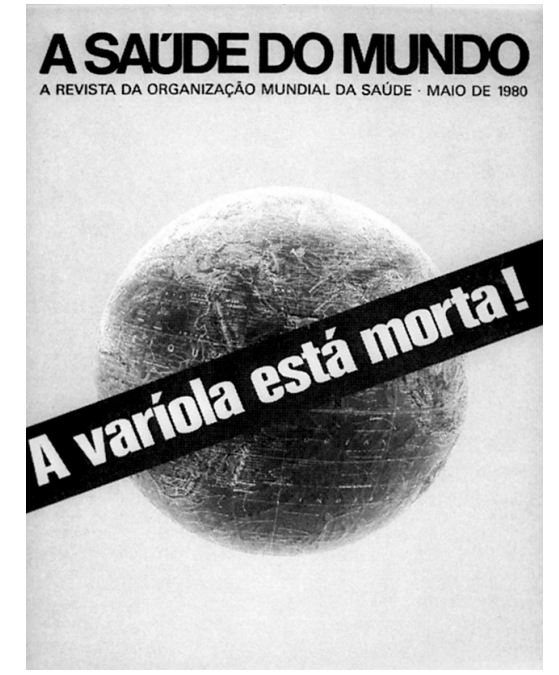

Capa da revista A Saúde do Mundo da OMS, maio de I980.

\begin{abstract}
A varíola foi a primeira doença infecciosa extinta da face da Terra pela
A história da vacina antivariólica merece ser relembrada pela magnitude da vitória alcançada e pela esperança que o método nos trouxe de obter a erradicação de outras doenças infecciosas.

Até o final do século xviII a varíola constituía verdadeiro flagelo humano, ceifando vidas ou desfigurando o rosto dos sobreviventes com cicatrizes indeléveis e perda de visão. Calcula-se que no século XviII houve, somente na Europa, sessenta milhões de vítimas de varíola (Ministério da Saúde, 2004).

A varíola foi introduzida no Brasil pelos colonizadores portugueses, vinda tanto da Europa como da África. A primeira epidemia de varíola ocorreu em I 563 , iniciando-se na Bahia e causando cerca de trinta mil mortes. Os indígenas eram particularmente vulneráveis e muitas tribos foram dizimadas por verdadeiras epidemias de varíola. Calcula-se que a varíola tenha ocasionado maior número de óbitos nos três primeiros séculos de colonização do que todas as outras doenças reunidas (Santos Filho, I99I, p. I62).
\end{abstract}


$\mathrm{Na}$ luta contra a varíola, os povos orientais utilizavam há mais de mil anos a chamada "variolização", que consistia na inoculação de material retirado das pústulas de um enfermo, na pele de um indivíduo são. Este adquiria a enfermidade em forma mais branda do que através do contágio natural. Contudo, apesar de sua relativa benignidade, a doença se manifestava com todo o seu cortejo sintomático, deixando, por vezes, cicatrizes no rosto e no corpo das pessoas inoculadas.

O método da variolização estendeu-se aos países do Ocidente no século XVIII, graças sobretudo à esposa do embaixador inglês em Constantinopla, lady Montagu, famosa por sua beleza e elegância, que foram afetadas pela varíola. Em I7I7 ela fez inocular seu filho de três anos de idade e, em I72I, já de volta à Inglaterra, sua filha de cinco anos. A corte real inglesa interessou-se pelo método, que passou a ser chamado de bizantino, em alusão à Bizâncio, antigo nome de Constantinopla (hoje Istambul). A variolização difundiu-se prontamente na Inglaterra e teve defensores ilustres em outros países, como Von Haller na Alemanha, Voltaire na França, e Benjamin Franklin nos Estados Unidos (Ujvari, 2003, pp. I30-I34).

Em I7 de maio de 1749 nascia na pequena cidade de Berkeley, na Inglaterra, Edward Jenner, predestinado a revolucionar o método de prevenção da varíola (Friedman e Friedland, 200I, pp. I02-I40; Bariety e Coury, I963, pp. 574-578). Submetido ele próprio, na infância, à variolização, o que mais o impressionou não foi tanto a inoculação em si, porém os preparativos para a mesma, que consistiam em sangria, purgativos e dieta de fome.

$\mathrm{Na}$ região de Gloucestershire, na Inglaterra, onde se localiza a cidade de Berkeley, o gado era acometido com frequência de uma doença com alguma semelhança com a varíola humana, conhecida por cowpox. As vacas afetadas por esta doença apresentavam vesículas e pústulas no ubre e as pessoas que as ordenhavam adquiriam a doença, manifestando lesões semelhantes nas mãos, lesões estas que desapareciam espontaneamente. Era observação corrente entre a população rural que as pessoas que adquiriam a cowpox ficavam protegidas da varíola humana, conhecida em inglês por smallpox.

Decidido a estudar medicina, Jenner frequentou inicialmente o serviço de um reputado médico, Ludlow, em Sodbury, onde certa vez ouviu uma paciente dizer: "eu não posso ter smallpox, pois já tive cowpox". Esta frase ficou retida em sua memória e foi o leitmotiv de todas as suas observações 
em anos posteriores. Transferindo-se para Londres a fim de dar continuidade aos seus estudos, conheceu o cirurgião e grande pesquisador John Hunter, de quem se tornou discípulo dileto e com quem adquiriu o gosto pela observação meticulosa e pela investigação científica. Voltando a clinicar em Berkeley, a ideia de proteger as pessoas contra a varíola humana (smallpox) por meio da varíola bovina (cowpox) tornou-se uma obsessão. Durante vinte anos, Jenner, pacientemente, colecionou observações que demonstravam que os indivíduos previamente contaminados pela doença bovina ficavam refratários à varíola.

Em maio de 1796 realizou a sua experiência definitiva. Uma mulher, de nome Sara Nelmes, havia adquirido a varíola bovina ordenhando vacas doentes. Jenner inoculou a linfa retirada de uma vesícula da mão direita de Sara Nelmes na pele do braço de um menino de oito anos, de nome Jacobo Phipps. A criança desenvolveu a conhecida reação eritêmato-pustulosa no local da escarificação e escassos sintomas gerais. Decorridas seis semanas Jenner inoculou o pus da varíola humana na criança, que não adquiriu a doença. Estava descoberta a vacina antivariólica.

Somente em I798, depois de ter inoculado com sucesso mais três pacientes, fez a sua primeira comunicação à Royal Society, de Londres, da qual era membro. Recebeu em resposta uma advertência de que "deveria zelar pelo bom conceito de que desfrutava na sociedade por suas comunicações anteriores e que não deveria arriscar o seu nome expondo ante a sábia Sociedade nada que estivesse em desacordo com os conhecimentos consagrados". As comunicações anteriores de Jenner a que aludia a Royal Society referiam-se à história natural do cuco, ave comum na Europa.

A atitude da Royal Society, uma respeitável instituição científica, pode parecer ridícula nos dias de hoje. Em todas as épocas, entretanto, as grandes inovações são recebidas com reserva e até hostilidade por seus contemporâneos. Os próprios amigos de Jenner, em Berkeley e em Londres, opuseram-se à ideia de inocular a vacina de origem bovina em seres humanos. Jenner chegou a ser ridicularizado.

Decidiu então publicar o resultado de suas observações por conta própria, sem aprovação da Royal Society, o que fez em um pequeno livro de 74 páginas, intitulado An Inquiry into the Causes and Effects of the Variolae Vaccinae, a Disease Discovered in Some of the Western Counties of England, Particularly Gloucestershire and Known by the Name of Cowpox (Investigação sobre as 
Causas e Efeitos da Varíola da Vaca, uma Doença Descoberta em Algumas Provincias a Oeste da Inglaterra, Particularmente Gloucestershire e Conhecida pelo Nome de Cowpox) (Friedman e Friedland, op. cit.).

Por algum tempo houve muita resistência e crítica ao método de Jenner. Parecia absurdo introduzir no corpo humano o germe de uma doença de animal. Apesar disso, a vacinação antivariólica difundiu-se por todo o mundo. Muito contribuiu para a sua credibilidade a decisão de Napoleão Bonaparte, que mandou vacinar o exército francês e promulgou um decreto a favor do novo método (Bariety, op. cit.). Jenner tornou-se famoso e o Parlamento inglês concedeu-lhe um prêmio de dez mil libras esterlinas em I 802 e outro de vinte mil libras em i 807 .

No Brasil, a vacinação antivariólica foi introduzida ainda no século XVIII, porém era praticada de maneira irregular e ao mesmo tempo combatida e rejeitada pela população. Os surtos epidêmicos continuaram ocorrendo no século XIX e a vacinação só se tornou efetiva a partir do século Xx, após a campanha iniciada no Rio de Janeiro por Oswaldo Cruz (Santos Filho, op. cit.).

Em I980, menos de duzentos anos após a descoberta da vacina, a Organização Mundial de Saúde declarava erradicada a varíola da face da Terra (Organização Mundial da Saúde, I980).

$\mathrm{O}$ adjetivo latino vaccinae (de vaca) foi substantivado e adaptado a todos os idiomas de cultura: inglês, vaccine; francês, vaccin; alemão, vakzine; espanhol, vacuna; italiano, vaccino; português, vacina. Por analogia, passou a designar todo inóculo dotado de ação antigênica, independente de sua origem. A vaca, considerada um animal sagrado em certas seitas religiosas da Índia, foi, assim, consagrada também pela ciência no termo vacina.

\section{Referências Bibliográficas}

Bariety, M. \& Coury, C. Histoire de la médecine. Paris, Fayard, I963.

Friedman, M. \& Friedland, G. W. As Dez Maiores Descobertas da Medicina. São Paulo, Companhia das Letras, 200I.

Ministério da SAÚde. Disponível em http://www.ccs.saude.gov.br/revolta/pdf/M5.pdf.

Organização Mundial da Saúde. A Saúde do Mundo, maio de I980.

Santos Filho, L. História Geral da Medicina Brasileira. São Paulo, Hucitec/Edusp, I99I.

Ujvari, S. C. A História e suas Epidemias, Rio de Janeiro, Senac Rio Editora, 2003. 